\title{
A NEW GENERALIZED REFINEMENT OF THE WEIGHTED ARITHMETIC-GEOMETRIC MEAN INEQUALITY
}

\section{Mohamed Amine Ighachane, Mohamed AkKouchi And El Hassan BENABDI}

Abstract. In this paper, we prove that for $i=1,2, \ldots, n, a_{i} \geqslant 0$ and $\alpha_{i}>0$ satisfy $\sum_{i=1}^{n} \alpha_{i}=1$, then for $m=1,2,3, \ldots$, we have

$$
\left(\prod_{i=1}^{n} a_{i}^{\alpha_{i}}\right)^{m}+r_{0}^{m}\left(\sum_{i=1}^{n} a_{i}^{m}-n \sqrt[n]{\prod_{i=1}^{n} a_{i}^{m}}\right) \leqslant\left(\sum_{i=1}^{n} \alpha_{i} a_{i}\right)^{m}
$$

where $r_{0}=\min \left\{\alpha_{i}: i=1, \ldots, n\right\}$. This is a considerable generalization of the two refinements of the arithmetic-geometric mean inequality due to Furuichi [2], Manasrah and Kittaneh [7], which correspond to the cases $m=1$ and $n=2$, respectively. As application we give some generalized inequalities of determinants for positive definite matrices.

Mathematics subject classification (2010): 26D07, 26D15, 15A45.

Keywords and phrases: Arithmetic-geometric mean inequality, Young inequality.

\section{REFERENCES}

[1] C. Berge, Principles of Combinatorics. Mathematics in Science and Engineering, Vol. 72, Edited by R. Bellman, Academic Press, New York, 1971.

[2] S. Furuichi, On refined Young inequalities and reverse inequalities, J. Math. Inequal., 5, 1 (2011), 21-31.

[3] G. H. Hardy, J. E. Littlewood and G. Pólya, Inequalities, 2nd ed., Cambridge Univ. Press, Cambridge, 1988.

[4] O. Hirzallah And F. KitTaneh, Matrix Young inequalities for the Hilbert-Schmidt norm, Linear Algebra Appl., 308 (2000), 77-84.

[5] R. A. Horn And C. R. Johnson, Matrix analysis, Cambridge Univ. Press, New-York, 1985.

[6] F. Kittaneh And Y. Manasrah, Improved Young and Heinz inequalities for matrices, J. Math. Anal. Appl., 361 (2010), 262-269.

[7] Y. Manasrah And F. Kittaneh, A generalization of two refined Young inequalities, Positivity, 19 (2015), 757-768. 